\title{
Advanced Internet of Things Irrigation Mechanism
}

\author{
Asjad Fahmi ${ }^{1}$ \\ Department of Electronics \& Communication Engineering \\ ADGITM, Delhi, India \\ Madhurima Sarkar ${ }^{2}$ \\ Department of Electronics \& Communication Engineering \\ ADGITM, Delhi, India
}

\author{
Atul Kumar Mishra ${ }^{3}$ \\ Department of Electronics \& Communication Engineering \\ ADGITM, Delhi, India \\ Maninder Bir Singh Gulshan ${ }^{4}$ \\ Department of Electronics \& Communication Engineering \\ ADGITM, Delhi, India
}

\begin{abstract}
Day-to-day performance in watering the plants is the most salient cultural enactment and the most labor-intensive task for the farmers as they don't have the knowledge about the technology. No matter whichever weather is, it is very crucial to control the amount of water outstretch the plants. So, it will efficacious to use an idea of automatic plant watering system which waters plants when they necessitate it. An important aspect of the project is: "When and How much of Water". This method is utilized to record the soil moisture level uninterruptedly and to decide whether watering is required or not, and how much water is essential in plant's soil.
\end{abstract}

Keywords-SIM 800L, NodeMCU v1.0, IoT, Google Firebase, Fritzing.

\section{INTRODUCTION}

Aim to design advanced Iot irrigation system is to update the people with the advance technology to make irrigation simpler and easier. Water above the necessity and below the necessity may damage the crops. For the effective use of water and save the plants it is necessary to develop a system which automatically or manually operated from anywhere according to the moisture of soil, temperature and humidity. This project is developed for two types of users

\section{- Android User}

\section{- Non Android User}

Android phone/smart phone user can monitor the moisture present in soil, temperature and humidity anytime and anywhere using smart phone application "irrigation system" and also turn on/ off water pump using application. Whereas the non-android user get an SMS alert when the soil moisture is below the threshold value and the user can also manually control the water pump using SMS/CALL service.

This system consist of a soil moisture sensor, temperature and humidity sensor, water pump , GSM module and NodeMCU .in which moisture sensor sense the moisture level of soil and if the moisture of soil is below the threshold value it automatically on the water pump and send the information to the application through NodeMCU and Google firebase and also send the information using SMS to non-android user phone.

\section{EXISTING MODEL}

For effective and proper use of water in agriculture there are many creative ideas and application comes in market. Some of such applications are:

A. Smart Irrigation System: This project consists of two modules solar pumping modules and automatic irrigation module. For saving electricity they proposed to utilize the solar energy from solar panels to automatically pump water depending on the intensity of sunlight [1].

B. Smart Irrigation System Based on Soil Moisture: This system consists of three major parts; humidity sensing, control section and the output section. The control unit was arduino board. The output is irrigation system which is depending on the soil moisture contents [2].

C. Microcontroller Based Automatic Plant Irrigation System: This system is based on microcontroller ATMEGA328, in which temperature and soil moisture sensors are placed in the field. Sensors sense the moisture content of the soil and give the information to farmer through GSM Module [3].

D. Water-Saving Irrigation System Based on Automatic Control by Using GSM Technology: In this system there are two divisions, one is field station and other is base station. Fieldstation sense parameters like temperatures and humidity and send parameters to base station, whereas base station analyze parameter for proper irrigation [4]

The main disadvantage of all systems are these are not available for all type of users present in the world and costly also, whereas the proposed system is for both type of users one is android user and other is non-android user. 


\section{PROPOSED MODEL}

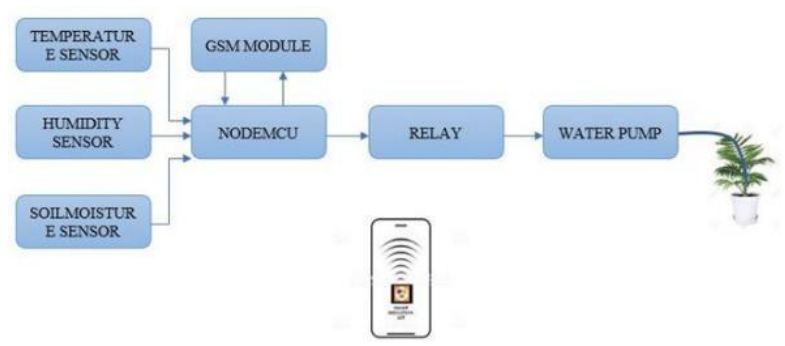

Fig. 1 Main Block Diagram

According to this system there are three unit'si.e. sensing unit, control unit and output unit. Temperature and humidity, soil moisture sensor is connected in sensing unit. NodeMCU works as control unit and water pump is output unit. Moisture sensor senses level of moisture present in soil and send information to control unit. Water pump supplies water to plants according to moisture condition of soil. An idea for GSM module in this project is to notify the user by sending SMS.

Flow Chart for the proposed model:

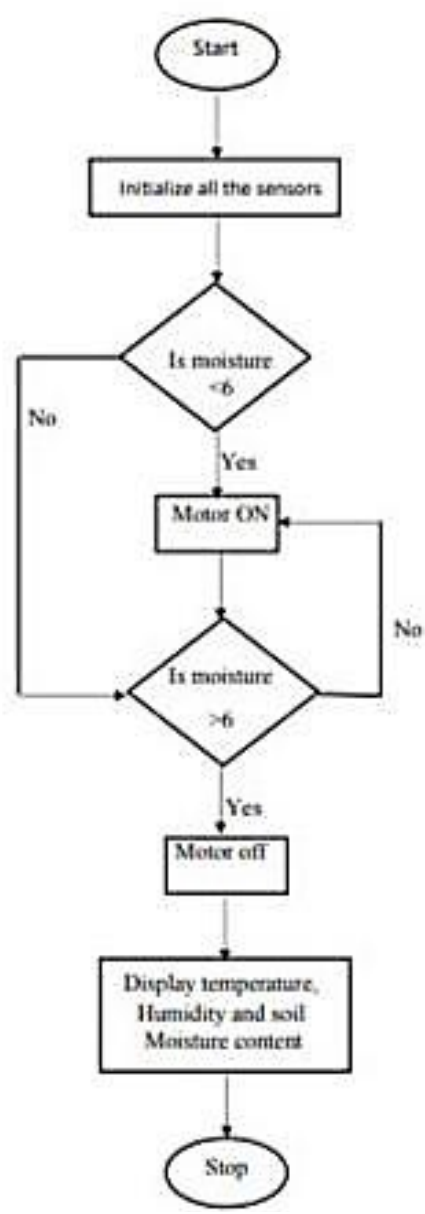

Fig.2: Flow Chart for the proposed model

\section{HARDWARE}

NodeMCU Dev Kit/board

ESP32 is a series of low-cost, low- power system on a chip micro-controllers with integrated $\mathrm{Wi}-\mathrm{Fi}$ and dualmode Bluetooth. The ESP32 series employs a Tensilica Xtensa LX6 microprocessor in both dual-core and singlecore variations and includes built-in antenna switches, RF balun, power amplifier, low-noise receive amplifier, filters, and power-management modules.

Features of the ESP32 include the following:

- Processors:

CPU: Xtensa dual-core (or single-core) 32-bit

LX6 microprocessor, operating at 160 or 240

$\mathrm{MHz}$ and performing at up to 600 DMIPS

Ultra low power (ULP) co-processor

- Memory: $520 \mathrm{KiB}$ SRAM

- Wireless connectivity:

Wi-Fi: $802.11 \mathrm{~b} / \mathrm{g} / \mathrm{n}$

Bluetooth: v4.2 BR/EDR and BLE

- Peripheral interfaces:

12-bit SAR ADC up to 18 channels

$2 \times 8$-bit DACs

$10 \times$ touch sensors (capacitive sensing

GPIOs)

$4 \times$ SPI

$2 \times \mathrm{I}^{2} \mathrm{~S}$ interfaces

$2 \times \mathrm{I}^{2} \mathrm{C}$ interfaces

$3 \times$ UART

SD/SDIO/CE-ATA/MMC/eMMC host controller

\section{SIM800L Module}

SIM800L is a miniature cellular module which allows for GPRS transmission, sending and receiving SMS and making and receiving voice calls. It supports Low cost and small footprint and quad band frequency.

- Supply voltage: $3.8 \mathrm{~V}-4.2 \mathrm{~V}$

- Recommended supply voltage: $4 \mathrm{~V}$

- Power consumption:

- $\quad$ sleep mode $<2.0 \mathrm{~mA}$ idle mode $<7.0 \mathrm{~mA}$

- GSM transmission (avg): $350 \mathrm{~mA}$

- GSM transmission (peek): 2000mA

- Module size: 25 x $23 \mathrm{~mm}$

- Interface: UART (max. 2.8V) and AT commands

- SIM card socket: microSIM (bottom side)

- Supported frequencies: Quad Band (850 / 950 / $1800 / 1900 \mathrm{MHz}$ )

- Antenna connector: IPX

- Status Signalling: LED

- Working temperature range: -40 do $+85^{\circ} \mathrm{C}$ 


\section{Soil Moisture Sensor}

The soil moisture sensor consists of two probes which are used to measure the volumetric content of water. The two probes allow the current to pass through the soil and then it gets the resistance value to measure the moisture value.

The soil Moisture sensor FC-28 has four pins

- VCC: For power

- A0: Analog output

- D0: Digital output

- GND: Ground

The Module also contains a potentiometer which will set the threshold value and then this threshold value will be compared by the LM393 comparator. The output LED will light up and down according to this threshold value.

The relation between the measured property and soil moisture must be calibrated and may vary depending on environmental factors such as soil type, temperature, or electric conductivity. Reflected microwave radiation is affected by the soil moisture and is used for remote sensing in hydrology and agriculture. Portable probe instruments can be used by farmers or gardeners.

Soil moisture sensors typically refer to sensors that estimate volumetric water content. Another class of sensors measure another property of moisture in soils called water potential; these sensors are usually referred to as soil water potential sensors and include tensiometers and gypsum blocks.

\section{Temperature and Humidity Sensor}

The DHT11 is a basic, ultra low-cost digital temperature and humidity sensor. It uses a capacitive humidity sensor and a thermistor to measure the surrounding air, and spits out a digital signal on the data pin (no analog input pins needed). It's fairly simple to use, but requires careful timing to grab data. The only real downside of this sensor is you can only get new data from it once every 2 seconds, so when using our library, sensor readings can be up to 2 seconds old.

Technical Details:

- 3 to $5 \mathrm{~V}$ power and $\mathrm{I} / \mathrm{O}$

- $2.5 \mathrm{~mA}$ max current use during conversion (while requesting data)

- Good for $20-80 \%$ humidity readings with $5 \%$ accuracy

- Good for $0-50{ }^{\circ} \mathrm{C}$ temperature readings $\pm 2^{\circ} \mathrm{C}$ accuracy

- No more than $1 \mathrm{~Hz}$ sampling rate (once every second)

- Body size $15.5 \mathrm{~mm}$ x $12 \mathrm{~mm}$ x $5.5 \mathrm{~mm}$

- 4 pins with $0.1 "$ spacing

\section{Water Pump}

Mini DC 3-6V Micro Submersible Pump Mini water pump For Fountain Garden Mini water circulation System DIY project. This is a low cost, small size Submersible Pump Motor which can be operated from a 3 $6 \mathrm{~V}$ power supply. It can take up to 120 liters per hour with very low current consumption of $220 \mathrm{~mA}$. Just connect tube pipe to the motor outlet, submerge it in water and power it. Make sure that the water level is always higher than the motor. Dry run may damage the motor due to heating and it will also produce noise.

\section{SOFTWARE}

\section{MIT App Inventor}

MIT App Inventor is a web application integrated development environment originally provided by Google, and now maintained by the Massachusetts Institute of Technology (MIT). It allows newcomers to computer programming to create application software (apps) for two operating systems (OS): Android, and iOS, which, as of 8 July 2019, is in final beta testing. It is free and open-source software released under dual licensing: a Creative Commons Attribution Share Alike 3.0 Unsorted license, and an Apache License 2.0 for the source code.

It uses a graphical user interface (GUI) very similar to the programming languages Scratch and the Star Logo TNG user interface, which allows users to drag and drop visual objects to create an application that can run on mobile devices. In creating App Inventor, Google drew upon significant prior research in educational computing, and work done within Google on online development environments.

Each component can have methods, events, and properties. Most properties can be changed by apps - these properties have blocks you can use to get and set the values. Some properties can't be changed by apps - these only have blocks you can use to get the values, not set them. In this document, read-only properties are shown in italics.

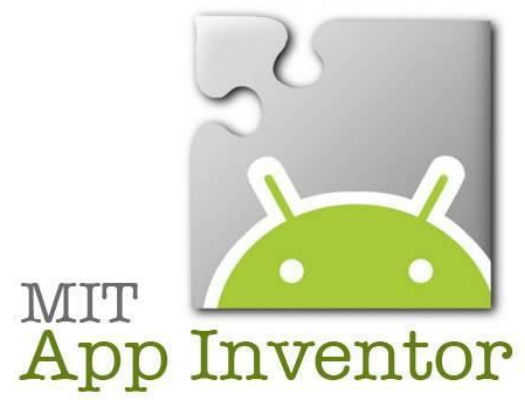

\section{Fritzing}

Fig. 3 MIT App Inventor[7]

It is an open-source initiative to develop amateur or hobby CAD software for the design of electronics hardware, to support designers and artists ready to move from experimenting with a prototype to building a more permanent circuit. It was developed at the University of Applied Sciences Potsdam. 
The software is created in the spirit of the Processing programming language and the Arduino microcontroller and allows a designer, artist, researcher, or hobbyist to document their Arduino-based prototype and create a PCB layout for manufacturing. The associated website helps users share and discuss drafts and experiences as well as to reduce manufacturing costs.

Fritzing can be seen as an electronic design automation (EDA) tool for non-engineers: the input metaphor is inspired by the environment of designers (the breadboard-based prototype), while the output is focused on accessible means of production. As of December 2, 2014 Fritzing has made a code view option, where one can modify code and upload it directly to an Arduino device.

Component images are distributed under CC-BYSA, which will also be the license for any generated breadboard views.

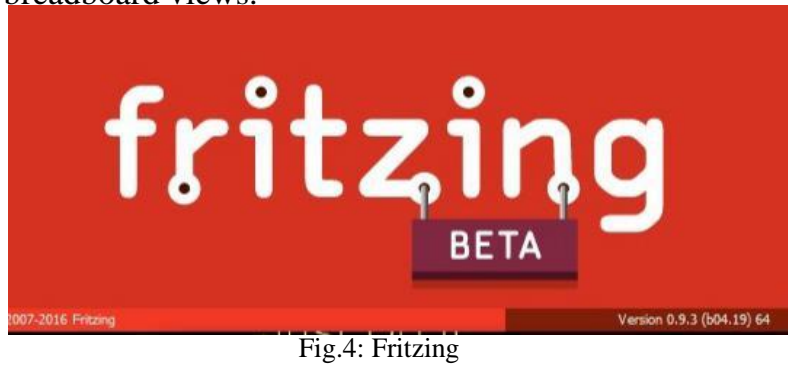

\section{Google Firebase}

Firebase is a mobile and web application development platform developed by Firebase, Inc. in 2011, then acquired by Google in 2014. As of October 2018, the Firebase platform has 18 products, which are used by 1.5 million apps.

Firebase evolved from Envolve, a prior startup founded by James Tamplin and Andrew Lee in 2011. Envolve provided developers an API that enables the integration of online chat functionality into their websites. After releasing the chat service, Tamplin and Lee found that it was being used to pass application data that weren't chat messages. Developers were using Envolve to sync application data such as game state in real time across their users.

Tamplin and Lee decided to separate the chat system and the real-time architecture that powered it.

They founded Firebase as a separate company in September 2011 and it launched to the public in April 2012.

- Analytics

Firebase Analytics

\section{- Develop}

Firebase Cloud Messaging, Firebase Auth

Firebase Realtime Database

Firebase Cloud Firestore

Firebase Storage

Firebase Hosting

ML Kit
- Stability

Firebase Test Lab for Android and iOS Admob

- Grow

Firebase Dynamic Links

\section{CIRCUIT DIAGRAM}

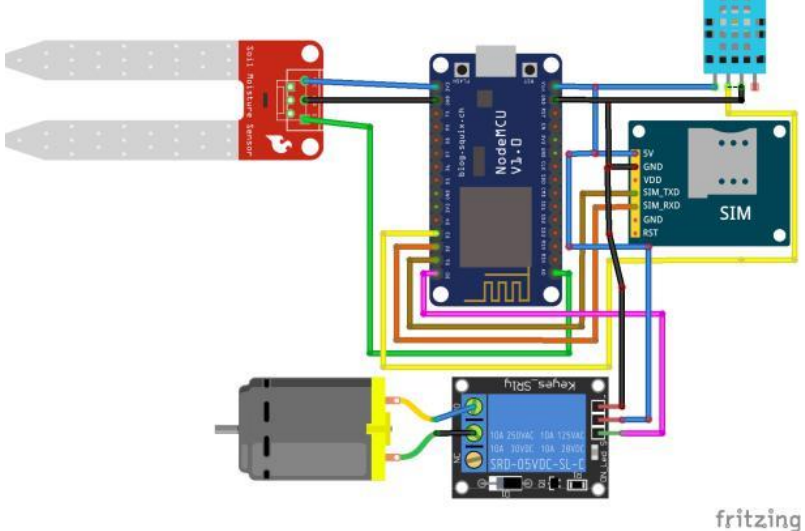

fritzing

Fig. 5: Circuit Diagram

The circuit diagram is designed using fritzing software. It is open source software for the design of electronics hardware. Project uses NodeMCU to control water pump and sending information to webapplication. It consists of relay module, water pump, GSM module and sensors. Moisture sensor FC-28 measures the level of soil moisture and sends the signal to NodeMCU ESP8266 then NodeMcu will open water pump if moisture is below the threshold value. DHT11 which is temperature and humidity sensor sense the temperature and humidity of the region and send information to control unit. SIM 800L is GSM/GPRS module used for sending/receiving SMS and voice calls. Through this when the moisture level is below the threshold value it sends an SMS alert to users phone. Operating voltage of SIM $800 \mathrm{Lis} 3.8 \mathrm{~V}-4.2 \mathrm{~V}$ for this DC to DC buck convertor is used which step down voltage. $5 \mathrm{~V}$ relay module is used following the Motor Pump which is use to switch the motor as required. When moisture is less than 6bar then motor switches to ON state otherwise it goes to OFF state. All this switching is maintained by relay module which contains optocoupler which is a noise canceller which helps to prevent motor damage. 


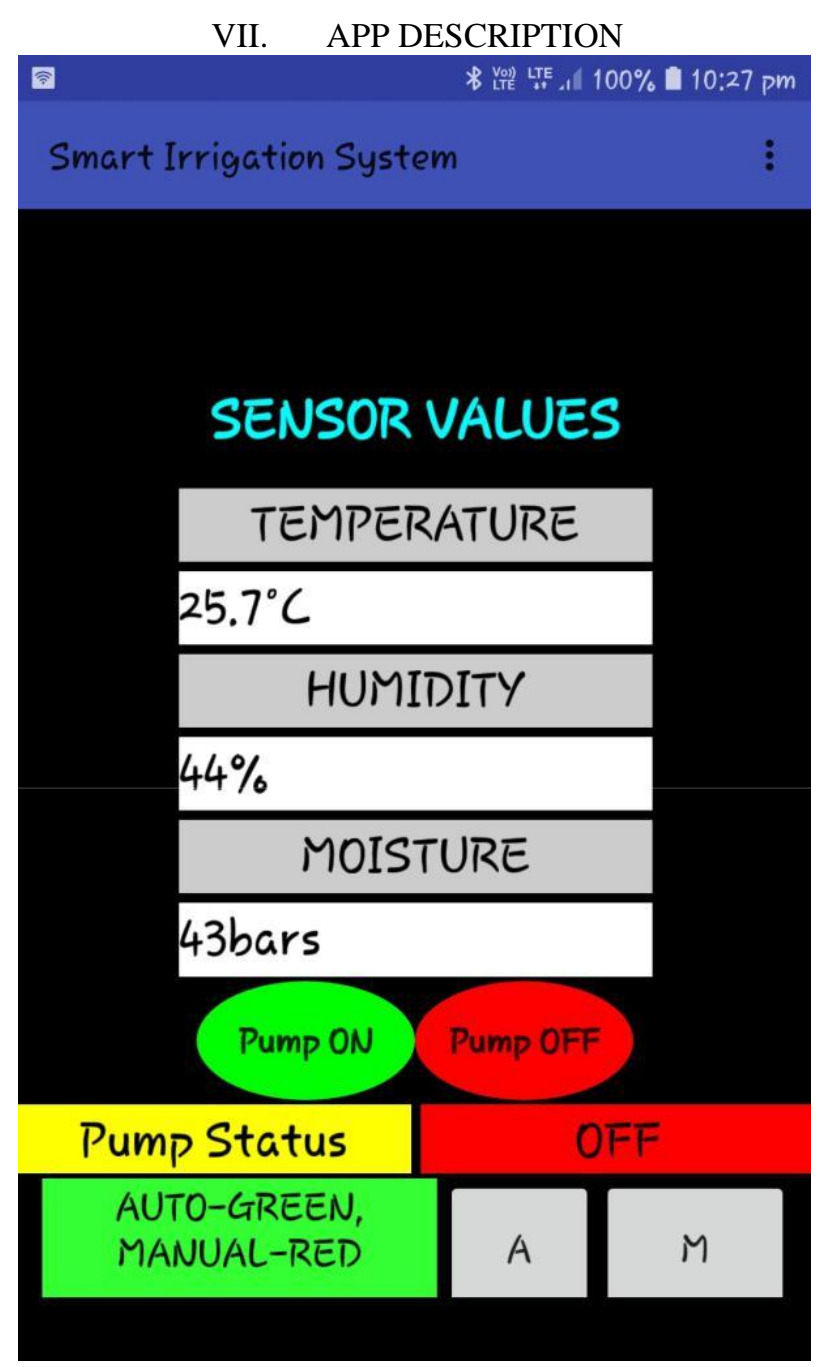

Fig. 6: App View

This web application is developed using MIT app inventor. In which sensor values are shown. In this two modes are present one is automatic mode and other is manual mode. From this app user can control and monitor their field anytime from anywhere. Users can also manually pump on and pump off after seeing the sensors value.

\section{CONCLUSION}

Main objective of this irrigation system is to make it more innovative, user friendly, time saving and more efficient then existing system for .measuring different parameters such as soil moisture, temperature, humidity etc. this system is very useful for both type of users to control and monitor their plants and fields from anywhere.

\section{REFERENCES}

[1]. Ravi kumar, Venu Gopal, Sridhar, Nagendra "Smart Irrigation System" International Journal of Pure and Applied Mathematics Volume 119 No. 15 2018, ISSN: 1314-3395

[2]. S Nalini Durga, M Ramakrishna "smart irrigation system based on soil moisture using IoT" International Research Journal of Engineering and Technology (IRJET) e-ISSN: 2395-0056 Volume: 05 Issue: 06 | June 2018

[3]. Bishnu Deo Kumar, Prachi Srivastava, Reetika Agrawal, Vanya Tiwari, "Microcontroller Based Automatic Plant Irrigation System," International Research Journal Of Engineering And Technology (IRJET) E-ISSN: 2395 -0056 Volume: 04 Issue: 05 | May -2017

[4]. K.S.S. Prasad, Nitesh Kumar, Nitish Kumar Sinha and Palash Kumar Saha "Water-Saving Irrigation System Based on Automatic Control by Using GSM Technology", Middle-East Journal of Scientific Research 12 (12): 1824-1827, 2012 ISSN 1990-9233.

[5]. Sonali D. Gainwar, Dinesh V. Rojatkar "Soil Parameters Monitoring With Automatic Irrigation System"International Journal of Science, Engineering and Technology Research (IJSETR), Volume 4, Issue 11, November 2015

[6]. Pavithra D. S, M. S .Srinath "GSM based Automatic Irrigation Control System for Efficient Use of Resources and Crop Planning by Using an Android Mobile" IOSR Journal of Mechanical and Civil Engineering (IOSR-JMCE)e-ISSN: 2278-1684,p-ISSN: 2320-334X, Volume 11, Issue 4 Ver. I (Jul- Aug. 2014)

[7]. https://appinventor.mit.edu/

[8]. S. Darshna, T.Sangavi, Sheena Mohan, A. Soundharya, Sukanya Desikan "Smart Irrigation System" IOSR Journal of Electronics and Communication Engineering (IOSR-JECE)e-ISSN: 22782834,p- ISSN: 2278-8735.Volume 10, Issue 3, Ver. II (May Jun.2015) 